\title{
Maxillary Sinus Lifting
}

\author{
${ }^{1} \mathrm{H}$ Yildiz, ${ }^{2} \mathrm{R}$ Barbaros, ${ }^{3}$ Nilsun Bagis
}

\section{ABSTRACT}

The use of dental implants in the restoration of toothless areas is quite common. However, in some cases, we can not use favorable implants in the maxillary molar region. This is because atrophy is observed following tooth extraction in this region. If an implant is desired in these areas, there may not be enough bone height, especially if the period between tooth extraction and implant construction is too long. In some cases, restorations are performed with short implants, curved implants, and zygoma implants, but these implants do not have sufficient strength against extreme occlusal forces. Therefore, augmentation of the maxillary sinus is required to use suitable implants, where the atrophied maxillary can be more resistant to occlusal forces in the molar region.

This review aims to evaluate the current methods and materials used in sinus augmentation and also explain about complications and treatments that are frequently encountered during and after the operation.

Keywords: Implant dentistry, Osseos surgery, Sinus lifting.

How to cite this article: Yildiz H, Barbaros R, Bagis N. Maxillary Sinus Lifting. Int J Experiment Dent Sci 2018;7(2):91-97.

Source of support: Nil

Conflict of interest: None

\section{BACKGROUND}

Dental implants are increasingly used in the restoration of partial and totally toothless areas. ${ }^{1}$ However, applying this treatment in maxillary posterior toothless regions is hampered by inadequate bone volume resulting in buccalpalatal and apical-coronal atrophy of the bone. ${ }^{2}$ With the pushing of molar teeth at the base of the sinus, osteoclastic activity increases, and bone loss accompanies the enlargement of the lower part of the maxillary sinus. ${ }^{3}$ Conventional non-regenerative therapies such as short implants, curved implants, pterygoid implants, and zygoma implants can be placed in posterior maxillary regions. ${ }^{4-7}$ Curved implants and short implants not quite suitable for the long-term survival and strong occlusal forces in this region, ${ }^{8}$ so implants of length and diameter more resistant to occlusal forces should be placed by regenerating the atrophic maxillary.

\footnotetext{
${ }^{1,2}$ Research Assistant, ${ }^{3}$ Associate Professor

${ }^{1-3}$ Department of Periodontology, Faculty of Dentistry, Ankara University, Ankara, Turkey

Corresponding Author: Nilsun Bagis, Associate Professor, Department of Periodontology, Faculty of Dentistry, Ankara University, Ankara, Turkey, Phone: 009031229656 40, e-mail: nilsunbagis@yahoo.com
}

Maxillary sinus augmentation was first reported by Tatum et al., ${ }^{9,10}$ and long-term results suggest that the technique is an effective treatment option. ${ }^{11}$

This compilation is intended to explain the current methods of sinus augmentation in cases where there is not enough volume for implantation in the intended region and to draw attention to the issues to be considered. ${ }^{12}$

\section{Indications of Sinus Lifting Operation}

- Oro-antral fistula treatment

- Reconstruction of palate clefts

- Interpositional graft with Le Fort I fractures

- Less than $10 \mathrm{~mm}$ alveolar residual bone height

- Less than $4 \mathrm{~mm}$ residual bone width

- No history of any pathology

- In the past, a major sinus disease has not been passed

\section{Local Contraindications of Sinus Lifting Operation}

- Maxillary sinus infections and pathological lesions

- Chronic sinusitis

- Alveolar scar possibility

- Odontogenic infections

- Allergic rhinitis

- The presence of an irregular alveolar crest

\section{General Contraindications of Sinus Lifting Operation}

- High doses of radiation in the head and neck region

- Sepsis

- Advanced medical conditions

- Uncontrolled systemic disturbances

- Excessive smoking, alcohol or substance consumption

- Psychological problems

\section{METHODS OF MAXILLARY SINUS LIFTING}

It can be entered from four different regions to the sinus area:

I. Superior-lateral wall (Caldwell-Luc): Entry from the anterior of the zygomatic arch.

II. Mid-lateral wall: Entered between alveolar crest and zygomatic arch.

III. Inferior-lateral wall: It is entered from alveolar crest level (Lateral window technique/external lifting)

IV. Krestal osteotomy (closed technique/internal lifting) 
The most commonly used methods in the clinic are an inferior-lateral wall and closed sinus lifting methods. External technique for creating a bone window in the vestibular wall of the sinus. After that, the sinus epithelium was gently raised to create a space for bone grafting. The healing period took about 6 months. In addition, the one-stage approach was demonstrated, in which sinus augmentation and implantation are performed in one surgery while the two-stage approach had the implantation taking place after several months of sinus augmentation. The abovementioned technique has been known as sinus lifting with the lateral window and is still widely used in modern implant dentistry due to its reliable efficiency.

\section{Lateral Window Technique (External Sinus Lifting)}

Side window technique, which is often used to reach the maxillary sinus and augment the area; the maxillary is the elevation of the sinus floor by obtaining a window-like cavity from the side wall of the sinus. Nerve blockage is achieved by local anesthesia for this procedure. A vertical incision is made at sagittal, mesial or distal (if necessary both sides) top of the crest. The lower edge of the window should be $3 \mathrm{~mm}$ above the sinus floor, the posterior edge on the tuber, and the anterior edge $3 \mathrm{~mm}$ distal from the anterior wall of the sinus. ${ }^{13}$

There are two methods used when creating windows on the sinus wall: (1) Incomplete fracture, (2) Removed bone wall method. In the incomplete fracture method, the sinus side wall is folded and placed in the sinus cavity. Thus, there is autogenous bone between the sinus floor and the graft material in the form of bone ischemia. In the bone wall removal method, the bone marrow is completely removed at the desired border. In both methods, after obtaining the sidewall window, the sinus membrane is removed from the bone using special instruments and carefully positioned if the graft material is to be placed. Thus, a vertical area is obtained between the sinus membrane and the alveolar crest.

Conventional rotary tools or piezoelectric are used while creating the sine sidewall window. Jordi et al. According to the study published in 2018, the perforation rate of the Schneiderian membrane is $24 \%$ in conventional procedures, whereas the rate of perforation in piezoelectric surgery is about $8 \% .{ }^{14}$

Many researchers have suggested the placement of membranes after surgery on the sinus lateral wall for the purpose of increasing new bone formation., ${ }^{9,15}$

\section{Internal Sinus Lifting}

Krestal osteotomy technique was first described by Summers in 1994 as a less invasive technique of apically compressing the sinus floor in the sinus direction and removing the Schneiderian membrane. ${ }^{16}$ This technique is a good option for patients with bone heights greater than 5-7 mm. ${ }^{13}$ Several studies have reported a good survival rate (from $93.5-100 \%$ ) for implants placed sinus using this technique. ${ }^{17}$

After removal of the osteotomy site either by flap removal or by flapless technique, a $2 \mathrm{~mm}$ drill is used to remove the bone from the sinus floor up to $1 \mathrm{~mm} .{ }^{17}$ The osteotomy is extended with osteotomy drills of $0.5-1.2$ $\mathrm{mm}$ from the implant size or a series of osteotomes. The bone particles are inserted into the osteotomy and gently pushed towards the sinus. The breaking of the sinus base can be detected by a change in resistance between the osteotomy and bone or by a change in the sound of the beat. As the membrane increases the risk of puncture, the osteotomy should be avoided from advancing into the sinus. ${ }^{16,17}$

Alveolar crest should be well assessed when the method is determined. Suggestions on this subject are: ${ }^{18}$

- $8 \mathrm{~mm}$ residual bone height and flat sinus floor: Standard implant placement.

- $\geq 8 \mathrm{~mm}$ residual bone height and sinus floor: Elevation of maxillary sinus floor using osteotomy technique without standard implant placement using a short implant or without graft material.

- 5-7 mm residual bone height and relatively flat sinus floor: Elevation of the maxillary sinus floor using osteotomy technique with resorption-resistant graft material.

- 5-7 mm residual bone height and oblique sinus floor: MaxilLary sinus floor elevation and simultaneous implant placement using the lateral approach with graft material

- 3-4 mm residual bone height and flat or oblique sinus floor: Elevation of maxillary sinus floor using the lateral approach with graft material.

- 1-2 mm residual bone height and flat or oblique sinus floor: Raising the maxillary sinus floor using a lateral approach with graft material and placement of delayed implant after 4-8 months.

\section{BIOMATERIALS USED IN MAXILLARY SINUS AUGMENTATION}

Sinus lifting was first described as a surgical technique for creating a bone window in the vestibular wall of the sinus. After that, the sinus epithelium was gently raised to create a space for bone grafting. Bone harvesting was performed in the iliac crest area and then placed 
in the prepared space. The healing period took about 6 months before implantation. The use of autogenous bone, allograft and alloplast material for bone grafting during sinus augmentation was suggested. ${ }^{19-32}$

Autogenous bone graft is accepted as the gold standard in terms of osteogenic potential but has some disadvantages due to reasons such as the limitations of obtaining autogenous bone graft from the mouth and morbidity as the donor site. ${ }^{33}$ Autogenous bone grafts are usually harvested from the oral cavity, iliac crest, tibia, and calvary. When choosing the donor site, the size of the defect and surgical risks should be considered. ${ }^{34,35}$

Demineralized freeze-dried bone (DFDB) began to be used in 1970 due to its osteoconductive properties. It has been observed that the use of periodontal surgeons is good for filling the defect and providing a significant increase in the formation of new attachment. ${ }^{36,37}$ Biocoral ${ }^{\circledR}$ in is the main component calcium carbonate, along with aragonite, strontium, fluoride, magnesium, sodium, and potassium. ${ }^{27-29}$ Biocoral has recently been used to treat bone defects that are associated with adult periodontitis. $^{31}$

Bioglass ${ }^{\circledR}$ contains $\mathrm{SiO}_{2}(45 \%), \mathrm{CaO}(24.5 \%), \mathrm{NaO}_{2}$ (24.5\%) and $\mathrm{P}_{2} \mathrm{O}_{5}(6 \%)$. Surface-reactive silica can provide specific physiological responses, including calcium and phosphate groups and alkaline $\mathrm{pH}$ levels, at interfaces with tissues, thereby providing high bioactivity and tolerances that are favorable for the formation of a strong implant bond. ${ }^{33,38}$

PepGen P-15 тм (Dentsply FriadentCeraMed, Lakewood, CO) is the combination of mineral components of the bovine bone. The inorganic bovine bone mineral component provides the calcium phosphate and natural anatomic matrix necessary for osteoconduction. ${ }^{39}$

Calcium sulfate is a highly bio-compatible material with one of the simplest of synthetic bone graft materials with the longest clinical history of more than 100 years. ${ }^{40-43}$ Calcium sulphate acts directly as a calcium source, and osteoprogenitor is faster to enter the cell than other materials. ${ }^{32,44}$

Bio-Oss ${ }^{\circledR}$ Protein-free sterilized bovine bone. It consists of porosity from 75 to $80 \%$ and cortical fragments with a crystal size of about $10 \mu \mathrm{m} .{ }^{45}$ According to some studies, Bio-Oss supports osteogenesis and has slow resorption. ${ }^{46-48}$

Fingranule $^{\circledR}$ (Fin-Ceramica, Faenza RA, Italy) is hydroxyapatite made from potato-shaped granules with a diameter ranging from 250 to $600 \mu \mathrm{m}$. This hydroxyapatite is characterized by very low density and crystallinity. The specific property of this material is that it has high porosity. The nano-size is between $10 \mu \mathrm{m}$ and $10-60 \mu \mathrm{m} .{ }^{49}$

Polymeric Gel; It consists of a special mixture of poloxamers dissolved in water (predominantly poloxamer 407;
BASF ChemTrade GmbH, Burgbernheim, Germany). An important feature of this mixture is that it remains liquid at $23^{\circ} \mathrm{C}$ and becomes denser and more solid at higher temperatures (about $\left.37^{\circ} \mathrm{C}\right)$. For this reason, the poloxamer mixture is stably positioned on the surface of the mucous membrane, allowing the sinus membrane to be raised in a stable manner. They are not metabolized in the body and are proven to be non-irritating and non-toxic. ${ }^{50}$

One of the most recent methods used in sinus lifting is the hyaluronic acid method. Hyaluronic acid, the application of exogenous hyaluronic acid and hyaluronic acid-based materials has provided good results in manipulating and accelerating the healing process in numerous medical disciplines such as ophthalmology, dermatology, dentistry, and rheumatology ${ }^{51}$ Hyaluronic acid is a naturally occurring, non-sulfated glycosaminoglycan ${ }^{52}$ normally found in large quantities in extracellular matrices such as basal lamina, connective matrix and synovial fluid. Hyaluronic acid also has osteoconductive properties and accelerates bone regeneration by chemically, proliferating, and rearranging differentiation of mesenchymal cells.

Scarano et al. ${ }^{53}$ compared the biomaterials used in sinus lifting in 2006. Results of this study, In every specimen taken from augmentations made with autogenous bone, it was possible to see that almost all particles of autogenous bone were completely surrounded by newly formed bone, and the material was found to be highly osteoconductive. They compared histomorphometric analyses of new bone formation: autogenous bone graft $40.1 \% \pm 3.2 \%$, demineralized frozen-dried bone $29 \% \pm$ $2.3 \%$, Biocoral ${ }^{\circledR} 39 \% \pm 3.1 \%$, Bioglass ${ }^{\circledR} 31 \% \pm 1.9 \%$, Fisiograft $^{\circledR}, 33 \% \pm 2.1 \%$, PepGen P-15 TM , 37\% $\pm 2.3 \%$, calcium sulfate $38 \% \pm 3.2 \%$, Bio-Oss $\AA \% \pm 1.6 \%$, hydroxyapatite $39,32 \% \pm 2.5 \%$.

Cossellu et al. ${ }^{50}$ used resorbable polymeric thermoreversible gels in place of graft material in their study of 11 patients who required maxillary sinus lift. After 6 months they took biopsies during implant placement and histologically and histomorphologically examined the specimens histologically and histomorphometrically. According to the histological study result, the new bone tissue does not contain fibrous tissue, cell infiltration is not seen. A new bone form, consisting of lamellar and woven bone, ranging from $54-60 \%$ was also observed.

Favato et al. ${ }^{54}$ found no statistically significant difference in the study of the volume changes of different graft materials in 43 patients with maxillary sinus augmentation. However, endobon is least shrunk graft material in this study.

Dogan et al. ${ }^{55}$ performed a comparison using microCT and histomorphometry on the early recovery period 
of collagenized heterolog bone graft (test group)alone and mixed with hyaluronic acid and collagenized heterolog bone graft (control group). Thirteen systemically healthy patients underwent bilateral sinus augmentation and one side was filled with collagenized heterolog bone graft alone while the other side was filled with hyaluronic acid + collagenized heterolog bone graft. Four months later, bone biopsies were obtained at the implant placement stage. According to the micro-CT and histomorphometric results, the test group had a significant difference from the control group in the 4-month improvement in new bone percentage. Micro-CT and histomorphometric analysis showed more bone formation on the side with hyaluronic acid.

Recent studies have shown that it is not necessary to use graft material in simultaneous implant placement with sinus lifting procedures and that filling the region between the sinus membrane and the bone-implant with the patient's blood will result in sufficient bone in that region. Thor et al. ${ }^{56}$ performed sinus elevation and implant placement without graft material at the same time. Sinus mucosa perforated in 11 of these 27 sinus operations. Sinus surgery was performed in patients with bone height $\leq 5$ $\mathrm{mm}$. The average amount of bone recovered as a result of 1-year follow-up was found to be $6.51 \mathrm{~mm}$.

Sindel et al. ${ }^{57}$ performed a study on the application of ring-block autogenous bone graft at implant placement with sinus perforation simultaneously. They prefer symphysis area to harvest autogenous bone graft. After removing the full thickness flap, graft borders were determined with a trephine bur with an inside diameter of $7.5 \mathrm{~mm}$. The implant cavity is prepared according to the diameter and length of the implant to be used on the later determined graft. In the drilling process, $1.5 \mathrm{~mm}$ bone tissue was not touched around the implant. After this procedure, a bone graft was removed using the same trephine bur.

The overall survival rate of the implants was $90 \%$ over an average of 24.3 months. The nine implanted implants continue to function within normal limits of marginal resorption without any sign of peri-implant disease.

\section{Complications of Sinus Lifting Operation}

We can classify complications frequently encountered in maxillary sinus augmentations as intra-operative and postoperative.

\section{Intraoperative Complications}

\section{Perforation of Sinus Membrane}

Perforation of the Schneiderian membrane is the most common complication in sinus lifting. The incidence during the lateral window approach ranges from $20-44 \%$. $^{58}$
Root shape structure may also be effective for perforation of the sinus membrane. The risk of perforation is greater when the sinus lift operations performed immediately after tooth extraction. If the maxillary sinuses are clearly seen on the radiograph, the sinus lifting operation is more suitable to be performed after at least 6 months instead of immediately after the tooth extraction. ${ }^{59}$

Schneiderian membrane may be associated with oral mucosa in some cases. When the alveolar bone completely disappeared in some places, sinus mucosa may be direct contact with oral mucosa. This can lead to large holes that are difficult to repair. ${ }^{60}$

A perforation therapy is to provide a stable coverage of the perforated area for graft material. The first step in the treatment of perforation is to raise the peripheral membrane ${ }^{13,61}$ to reduce tension on the area and prevent further perforation. If a perforation is small, the sinus membrane has the chance to repair itself by forming a clot or foldovern. ${ }^{62}$ If greater (>5 mm), it should be covered with an absorbable membrane that serves as a barrier between the sinus and the graft material. When placing graft material, it is important to stabilize the barrier over the perforated area to limit the possible movement of the membrane. ${ }^{62}$ In large openings (>10 mm), it is recommended to use a large resorbable membrane that extends over the lateral wall and stabilizes with the seam. ${ }^{63}$

\section{Bleeding}

Surgical intervention of one of the vessels may not be a life-threatening event, but it may make the procedure difficult because of the more difficult imaging of the Schneiderian membrane. Although maxilla is intensely vascularized in young and balanced populations, the blood flow to the bone is permanently reduced with age and progressive atrophy, and the number of vessels and diameters are reduced.

Elian et al., ${ }^{64}$ the distance between the intraosseous anastomosis and the alveolar crete were $19 \mathrm{~mm}$. To insert implants with a length of $12 \mathrm{~mm}$, cuts should be made about $14 \mathrm{~mm}$ above the alveolar crest. According to CT scan data, $80 \%$ of the arteries are located more than 15 $\mathrm{mm}$ from the crest and are not at risk for a potential surgical complication. However, when the alveolar crest is severely resorbed, the vessels will be close to the crest according to the reported mean.

\section{Postoperative Complications}

Grafted sinus infection is a rare complication. According to the study of Pjetursson et al., ${ }^{18}$ the prevalence of infection was $2.9 \% .^{18,65}$ Infection of grafted sinuses typically occurs 3-7 days after surgery. It is seen on days and can 
lead to graft failure. A possible complication of infection is paresis of the infection with the spread to the eye pit or even to the brain.

For this reason, infected sinus grafts should be treated immediately and aggressively. Removal of the entire graft from the sinus cavity and high doses of antibiotics are required. Causes of late failure include chronic infection, loss of grafts, loss of whole graft, oroantral fistula, soft touch from the lateral window, granulation tissue graft displacement, and sinus cysts. ${ }^{18}$

\section{POSTSURGICAL PROCEDURES}

Less trauma during the surgical procedure is important for the relief of postoperative pain complaints. The swelling to the base of the eye on the face of the patient occurs in most cases. Applying cold compresses to the postoperative region will play an important role in reducing swelling. Post-surgical care is also important for wound healing and infection. After surgery, antibiotic prophylaxis is performed. Also, painkillers and non-steroidal anti-inflammatory drugs are prescribed. In addition, for the first 3 weeks, antiseptic mouthwash with $0.1-0.2 \%$ chlorhexidine twice a day is needed. Since graft material can cause air pressure to displace the patient, it is advisable not to force the patient to clean the nose and not to close the mouth when sneezing. ${ }^{17}$

\section{ALTERNATIVE TECHNIQUES}

Despite the reliability and efficiency of various sinus augmentation techniques, there is still a high rate of complications and complexity for such procedures. With the advances in technology and improvements in the design and manufacture of implants, some alternative concepts suggested implantation without sinus augmentation could be possible.

The use of a tilted (angulated) implant in the posterior maxilla was suggested to avoid sinus augmentation. In this study, an evaluation was made to compare the efficiency between tilted and axial implants with no sinus grafting. After 5 years of follow-up, the implant success rate was $95.2 \%$ (survival: rate $100 \%$ ) for the tilted implants and $91.3 \%$ (survival rate $96.5 \%$ ) for the axial implants. The average marginal bone loss was $1.21 \mathrm{~mm}$ for the tilted implants and $0.92 \mathrm{~mm}$ for the axial ones. ${ }^{66}$ The concept of using a tilt implant was further enhanced. Transsinus tilted implants, with the implant body inside the sinus, were utilized in the all-on- 4 concept for complete edentulous maxilla patients. A survival rate of $96.4 \%$ was achieved at the implant level. The survival rate of prostheses was $100 \%$. Sinusitis occurred in two patients $(2.9 \%)$. The high survival rate and low complication rate suggest that trans-sinus implants could be an alternative solution to avoid sinus augmentation. ${ }^{67}$

Zygomatic implants offer another option treatment modality to sinus augmentation. Almost similar to trans-sinus tilted implants, zygomatic implants are long implants that pass through the sinus or laterally to the sinus. ${ }^{68}$ The difference was the anchorage position. While the tip of a trans-sinus tilted implant is positioned in the bone between the anterior sinus wall and the nasal cortical bone, ${ }^{67}$ a zygomatic implant will anchor itself into the zygomatic process for stability.

The use of a short implant (4-8 mm long) was also an interesting and straight forward alternate treatment modality for sinus augmentation followed by longer implant placement. In a recent systematic review, there was further clarification of this concept. Eight RCTs from an initial search count of 851 titles were selected, and data extraction was performed. Both long-term follow-up (16-18 months) and short-term follow-up (8-9 months) study showed no significant differences when comparing implant survival rates. Most common complications were membrane perforations, and they were almost three times higher for longer implants in the augmented sinus compared to shorter implants. Morbidity, surgical time, and cost-effectiveness also showed more favorable data in the shorter implant group. ${ }^{69}$

\section{CONCLUSION}

Sinus augmentation is the most common indication associated with implant placement in patients with severe edentulous maxilla. With the advancement of implant dentistry, there have been introductions of new techniques and grafting materials, which were aimed to improve the treatment outcomes of sinus augmentation. Several new concepts, such as the use of an angulated implant, zygomatic implant, or short implant, could provide another option for implantation in the posterior maxilla without the need for sinus augmentation, thus making treatment time shorter and reducing the rate of complications and the complexity of the treatment procedure.

\section{REFERENCES}

1. Lee WJ, Lee SJ, Kim S. Analysis of location and prevalence of maxillary sinus septa. J Periodontal Implant Sci 2010;40(2):56-60.

2. Furst G, Gruber R, Tangl S, et al. Sinus grafting with autogenous platelet-rich plasma and bovine hydroxyapatite. A histomorphometric study in minipigs. Clin Oral Implants Res 2003;14(4):500-508.

3. Kim MJ, Jung UW, Kim CS, et al. Maxillary sinus septa: prevalence, height, location, and morphology. A reformatted computed tomography scan analysis. J Periodontol. 2006;77(5):903-908. 
4. Asawa N, Bulbule N, Kakade D, et al. Angulated Implants: An Alternative to Bone Augmentation and Sinus Lift Procedure: Systematic Review. J Clin Diagn Res 2015;9(3):ZE10-ZE13.

5. Lombardo G, D'Agostino A, Trevisiol L, et al. Clinical, microbiologic and radiologic assessment of soft and hard tissues surrounding zygomatic implants: a retrospective study. Oral Surg Oral Med Oral Pathol Oral Radiol 2016;122(5):537-546.

6. Candel E, Penarrocha D, Penarrocha M. Rehabilitation of the atrophic posterior maxilla with pterygoid implants: a review. J Oral Implantol 2012;38 Spec No:461-466.

7. Fan T, Li Y, Deng WW, et al. Short Implants ( 5 to $8 \mathrm{~mm}$ ) Versus Longer Implants $(>8 \mathrm{~mm}$ ) with Sinus Lifting in Atrophic Posterior Maxilla: A Meta-Analysis of RCTs. Clin Implant Dent Relat Res 2017;19(1):207-215.

8. Chiapasco M, Casentini P, Zaniboni M. Bone augmentation procedures in implant dentistry. Int J Oral Maxillofac Implants 2009;24 Suppl:237-259.

9. Tatum HJ. Maxillary and sinus implant reconstructions. Dent Clin North Am. 1986;30(2):207-229.

10. Tatum OHJ, Lebowitz MS, Tatum CA, et al. Sinus augmentation. Rationale, development, long-term results. NY State Dent J. 1993;59(5):43-48.

11. Triplett RG, Schow SR. Autologous bone grafts and endosseous implants: complementary techniques. J Oral Maxillofac Surg 1996;54(4):486-494.

12. Bloch VP, Rosenlicht JL. Sinus lift as a means of improving restorative options in the edentulous maxilla: a case report. J N J Dent Assoc 1993;64(2):23-25,27.

13. Tarnow DP, Wallace SS, Froum SJ, et al. Histologic and clinical comparison of bilateral sinus floor elevations with and without barrier membrane placement in 12 patients: Part 3 of an ongoing prospective study. Int J Periodontics Restorative Dent 2000;20(2):117-125.

14. Jordi C, Mukaddam K, Lambrecht JT, et al. Membrane perforation rate in lateral maxillary sinus floor augmentation using conventional rotating instruments and piezoelectric device—a meta-analysis. Int J Implant Dent 2018;4:3.

15. Wallace SS, Mazor Z, Froum SJ, et al. Schneiderian membrane perforation rate during sinus elevation using piezosurgery: clinical results of 100 consecutive cases. Int J Periodontics Restorative Dent 2007;27(5):413-419.

16. Summers RB. Sinus floor elevation with osteotomes. J Esthet Dent 1998;10(3):164-171.

17. Pjetursson BE, Lang NP. Sinus floor elevation utilizing the transalveolar approach. Periodontol 2000. 2014;66(1):59-71.

18. Lindhe J, Lang, NP. Clinical periodontology and implant dentistry. 2008; $6^{\text {th }}$ edition Oxford: Blackwell Munksgaard.

19. Tong DC, Rioux K, Drangsholt M, et al. A review of survival rates for implants placed in grafted maxillary sinuses using meta-analysis. Int J Oral Maxillofac Implants 1998;13(2):175182.

20. Jensen OT, Greer R. Immediate placement of osseointegrating implants into the maxillary sinus augmented with mineralized cancellous allograft and Gore-Tex: Second-stage surgical and histological findings. In: Laney WR, Tolman DE, eds. Tissue Integration in Oral, Orthopedic \& Maxillofacial Reconstruction: Proceedings of the Second International Congress on Tissue Integration in Oral, Orthopedic, and Maxillofacial Reconstruction, Mayo Medical Center, Rochester, Minnesota, September 23-27, 1990. Chicago, IL: Quintessence; 1992:321333.21.

21. Jensen OT. Allogeneic bone or hydroxylapatite for the sinus lift procedure? J Oral Maxillofac Surg 1990;48(7):771.
22. Becker W, Becker BE, Polizzi G. Autogenous bone grafting of bone defects adjacent to implants placed into immediate extraction sockets in patients: A prospective study. J Oral Maxillofac Surg 1994:389-396.

23. Becker W, Schenk R, Higuchi K, et al. Variations in bone regeneration adjacent to implants augmented with barrier membranes alone or with demineralized freeze-dried bone or autologous grafts: a study in dogs. Int J Oral Maxillofac Implants 1995;10(2):143-154.

24. Piattelli A, Scarano A, Corigliano M, et al. Comparison of bone regeneration with the use of mineralized and demineralized freeze-dried bone allografts: a histological and histochemical study in man. Biomaterials 1996;17(11):1127-1131.

25. Donath K, Piattelli A. Bone tissue reactions to demineralized freeze-dried bone in conjunction with e-PTFE barrier membranes in man. Eur J Oral Sci 1996;104(2 ( Pt 1)):96-101.

26. Jensen OT, Shulman LB, Block MS, et al. Report of the Sinus Consensus Conference of 1996. Int J Oral Maxillofac Implants 1998;13 Suppl:11-45.

27. Yukna RA. Clinical evaluation of coralline calcium carbonate as a bone replacement graft material in human periodontal osseous defects. J Periodontol 1994;65(2):177-185.

28. Pollick S, Shors EC, Holmes RE, et al. Bone formation and implant degradation of coralline porous ceramics placed in bone and ectopic sites. J Oral Maxillofac Surg 1995;53(8):913915.

29. Roudier M, Bouchon C, Rouvillain JL, et al. The resorption of bone-implanted corals varies with porosity but also with the host reaction. J Biomed Mater Res 1995;29(8):909-915.

30. Wikesjo UME, Lim WH, RaziSS, et al. Periodontal repair in dogs: a bioabsorbable calcium carbonate coral implant enhances space provision for alveolar bone regeneration in conjunction with guided tissue regeneration. J Periodontol 2003;74(7):957-964.

31. Yukna RA, Yukna CN. A 5-year follow-up of 16 patients treated with coralline calcium carbonate (Biocoral) bone replacement grafts in intrabony defects. J Clin Periodontol 1998;25:1036-1040.

32. Piattelli A, Scarano A, Piattelli M, et al. Bone regeneration using Bioglass: an experimental study in rabbit tibia. J Oral Implantol 2000;26(4):257-261.

33. Wang M. Developing bioactive composite materials for tissue replacement. Biomaterials 2003;24(13):2133-2151.

34. Clavero J, Lundgren S. Ramus or chin grafts for maxillary sinus inlay and local onlay augmentation: comparison of donor site morbidity and complications. Clin Implant Dent Relat Res 2003;5(3):154-160.

35. Cricchio G, Lundgren S. Donor site morbidity in two different approaches to anterior iliac crest bone harvesting. Clin Implant Dent Relat Res 2003;5(3):161-169.

36. Blumenthal N, Steinberg J. The use of collagen membrane barriers in conjunction with combined demineralized bone-collagen gel implants in human infrabony defects. J Periodontol 1990;61(6):319-327.

37. Bowers G, Felton F, Middleton C, et al. Histologic comparison of regeneration in human intrabony defects when osteogenin is combined with demineralized freeze-dried bone allograft and with purified bovine collagen. J Periodontol 1991;62(11):690-702.

38. Nasr HF, Aichelmann-Reidy ME, Yukna RA. Bone and bone substitutes. Periodontol 2000 1999;19:74-86.

39. Qian JJ, Bhatnagar RS. Enhanced cell attachment to anorganic bone mineral in the presence of a synthetic peptide related to collagen. J Biomed Mater Res 1996;31(4):545-554. 
40. Peltier LF, Bickel EY, Lillo R, et al. The Use of Plaster of Paris to Fill Defects in Bone. Ann Surg 1957;146(1):61-69.

41. Alderman NE. Sterile plaster of paris as an implant in the infrabony environment: a preliminary study. J Periodontol 1969;40(1):11-13.

42. Shaffer CD, App GR. The use of plaster of paris in treating infrabony periodontal defects in humans. J Periodontol 1971;42(11):685-690.

43. Sottosanti JS. Calcium sulfate-aided bone regeneration: a case report. Periodontal Clin Investig 1995;17(2):10-15.

44. Tay BK, Patel V, Bradford DS. Calcium sulfate- and calcium phosphate-based bone substitutes. Mimicry of the mineral phase of bone. Orthop Clin North Am 1999;30(4):615-623.

45. Berglundh T, Lindhe J. Healing around implants placed in bone defects treated with Bio-Oss. An experimental study in the dog. Clin Oral Implants Res. 1997;8(2):117-124.

46. Piattelli M, Favero GA, Scarano A, et al. Bone reactions to anorganic bovine bone (Bio-Oss) used in sinus augmentation procedures: a histologic long-term report of 20 cases in humans. Int J Oral Maxillofac Implants 1999;14(6):835-840.

47. Valentini P, Abensur D. Maxillary sinus floor elevation for implant placement with demineralized freeze-dried bone and bovine bone (Bio-Oss): a clinical study of 20 patients. Int J Periodontics Restorative Dent 1997;17(3):232-241.

48. Rodriguez A, Anastassov GE, Lee H, et al. Maxillary sinus augmentation with deproteinated bovine bone and platelet rich plasma with simultaneous insertion of endosseous implants. J Oral Maxillofac Surg 2003;61(2):157-163.

49. Nanci A, Zalzal S, Fortin M, et al. Incorporation of circulating bone matrix proteins by implanted hydroxyapatite and at bone surfaces: Implications for cement line formation and structuring of biomaterials. In: Davies JE, ed. Proceedings of the International Workshop on Bone Engineering. Toronto, Canada: Em Squared Inc.; 2000:305-311.

50. Cossellu G, Farronato G, Farronato D, et al. Space-maintaining management in maxillary sinus lifting: a novel technique using a resorbable polymeric thermo-reversible gel. Int J Oral Maxillofac Surg 2017;46(5):648-654.

51. Laurent TC, Fraser JR. Hyaluronan. FASEB J 1992;6(7):23972404.

52. Benedetti L, Cortivo R, Berti T, et al. Biocompatibility and biodegradation of different hyaluronan derivatives (Hyaff) implanted in rats. Biomaterials 1993;14(15):1154-1160.

53. Scarano A, Degidi M, Iezzi G, et al. Maxillary sinus augmentation with different biomaterials: a comparative histologic and histomorphometric study in man. Implant Dent 2006;15(2):197-207.

54. Favato MN, Vidigal BCL, Cosso MG, et al. Impact of human maxillary sinus volume on grafts dimensional changes used in maxillary sinus augmentation: a multislice tomographic study. Clin Oral Implants Res 2015;26(12):1450-1455.

55. Dogan E, Dursun E, Tosun E, et al. Evaluation of hyaluronic matrix efficacy in sinus augmentation: a randomized-con- trolled histomorphometric and micro-computed tomography analysis. Int J Oral Maxillofac Surg 2017;46(7):931-937.

56. Thor et al. Sinus Lift and Immediate Implant Installation. J Oral Maxillofac Surg 2007.

57. Sindel A, Ozarslan MM, Ozalp O. Intrasinusal locking technique: a novel use of the ring block technique at sinus perforations for simultaneous implant placement. Int J Oral Maxillofac Surg 2018;47(4):499-504.

58. Zijderveld SA, van den Bergh JPA, Schulten EAJM, et al. Anatomical and surgical findings and complications in 100 consecutive maxillary sinus floor elevation procedures. J Oral Maxillofac Surg 2008;66(7):1426-1438.

59. Zijderveld et al. Complications in Maxillary Sinus Floor Elevation Procedures. J Oral Maxillofac Surg 2008;66(8):0-180.

60. van den Bergh JP, ten Bruggenkate CM, Disch FJ, Tuinzing DB. Anatomical aspects of sinus floor elevations. Clin Oral Implants Res 2000;11(3):256-265.

61. Testori T, Wallace SS, Del Fabbro M, et al. Repair of large sinus membrane perforations using stabilized collagen barrier membranes: surgical techniques with histologic and radiographic evidence of success. Int J Periodontics Restorative Dent 2008;28(1):9-17.

62. Vlassis JM, Fugazzotto PA. A classification system for sinus membrane perforations during augmentation procedures with options for repair. J Periodontol 1999;70(6):692-699.

63. Karabuda C, Arisan V, Ozyuvaci H. Effects of sinus membrane perforations on the success of dental implants placed in the augmented sinus. J Periodontol 2006;77(12): 1991-1997.

64. Elian N, Wallace S, Cho S-C, et al. Distribution of the maxillary artery as it relates to sinus floor augmentation. Int J Oral Maxillofac Implants 2005;20(5):784-787.

65. Tan WC, Lang NP, Zwahlen M, et al. A systematic review of the success of sinus floor elevation and survival of implants inserted in combination with sinus floor elevation. Part II: transalveolar technique. J Clin Periodontol 2008;35(8 Suppl):241-254.

66. Aparicio C, Perales P, Rangert B. Tilted implants as an alternative to maxillary sinus grafting: a clinical, radiologic, and periotest study. Clin Implant Dent Relat Res. 2001;3:39-49

67. Maló P, de Araújo NM, Lopes A. Immediate loading of Allon-4' maxillary prostheses using trans-sinus tilted implants without sinus bone grafting: a retrospective study reporting the 3-year outcome. Eur J Oral Implantol 2013;6:273-283.

68. Branemark PI, Grondahl K, Ohrnell LO, et al. Zygoma fixture in the management of advanced atrophy of the maxilla: technique and long-term results. Scand J Plast Reconstr Surg Hand Surg 2004;38:70-85.

69. Thoma DS, Zeltner M, Husler J, et al. EAO Supplement Working Group 4-EAO CC 2015 short implants versus sinus lifting with longer implants to restore the posterior maxilla: a systematic review. Clin Oral Implants Res 2015;26: 154-169. 